\title{
Uma análise sobre corpos periféricos, normais e anormais a partir do filme pieles
}

\author{
Leandro Faustino Polastrini \\ Luciene Neves
}

\section{Resumo:}

Buscamos neste artigo realizar uma análise sobre os termos normalidade, anormalidade, corporalidade central e periférica através do filme "Pieles" (2017) do diretor espanhol Eduardo Casanova. Para realizar este trabalho utilizamos a metodologia bibliográfica e análise fílmica. Destarte, apresentamos a descrição sobre o filme e algumas personagens, desenvolvemos uma discussão teórica e fechamos com análises sobre o filme e as considerações finais. Concluímos que não são as diferenças corpóreas, sejam elas anomalias ou mutações congênitas que definem os lugares e funções desses corpos diferentes na sociedade, mas sim os padrões, normas e convenções construídas histórico-socialmente.

Palavras-chave: corpos periféricos, anormal, normal.

\section{Resumen:}

Buscamos en este artículo realizar un análisis acerca de los términos normalidad, anormalidad, corporalidad central y periférica a través de la película Pieles (2017) del director español Eduardo Casanova. En la realización de este trabajo utilizamos la metodología bibliográfica y análisis fílmico. De este modo, presentamos la descripción de la película y algunos de sus personajes, desarrollamos una discusión teórica y cerramos con el análisis del film y las consideraciones finales. Concluimos que no son las diferencias corpóreas, sean ellas anomalías o mutaciones congénitas que definen los lugares y funciones de estos cuerpos diferentes en la sociedad, sino los patrones, normas y convenciones construidas histórico-socialmente.

Palabras Clave: cuerpos periféricos, anormal, normal. 


\section{Introdução}

Este trabalho tem como objetivo refletir e discutir sobre os conceitos de corpo, normalidade e anormalidade a partir filme Pieles (2017) do diretor espanhol Eduardo Casanova. Pieles é um filme que não está nos padrões dos filmes classificados como "comerciais". De acordo com crítico de cinema Gustavo Hackaq (2017) "não é um filme comercial e não será largamente aceito pelo público, mas é um estudo brilhante dos desejos mais profundos do homem, enlatados em 50 tons de rosa".

O filme apresenta personagens com malformações congênitas e um com deformidade física decorrente de acidente do tipo queimadura, também há dois casos de patologias psicológicas, sendo um personagem com disforia corporal e outro em que a trama leva a entender como sendo um pedófilo. Um traço muito marcante entre a maioria dos personagens é a difícil forma de lidar com o corpo e a sexualidade, muito disso em razão de não estarem dentro dos padrões de normalidade anatômica.

Destarte, para esta análise discutiremos sobre a construção de corpos periféricos a partir das concepções de normalidade e anormalidade como constructos que perpassam os campos do biológico, do cultural e do sócio histórico. Para tanto, a metodologia adotada para este trabalho é de caráter bibliográfico, descritivo e análise fílmica.

No primeiro momento faremos uma descrição do filme e seus personagens, depois trataremos sobre o copo e suas concepções a partir da modernidade por meio de bases teóricas forjadas pelos seguintes autores: Rocha e Rodrigues (2016) com "Corpo e consumo: roteiro de estudos e pesquisa"; Fernandes e Barbosa (2016) com "A construção dos corpos periféricos" e Foucault (1987) em "Vigiar e punir". Continuaremos a discussão com um enfoque sobre o normal e anormal, para o qual utilizamos como fundamentação os seguintes teóricos: Canguilhem (2009) em seu o livro "O normal e patológico"; Foucault (2001) com o livro "Os anormais" e Platt (2014) como o artigo "Constructo conceitual de 
normalidade/anormalidade (ou adequação social)". Por fim, faremos algumas análises sobre a construção de corpos periféricos e a problematização sobre o normal e anormal no filme Pieles.

\section{O filme e seus personagens}

Destacamos que o filme se desenvolve por meio de quadros, ou seja, ações/cenas separadas de cada personagem, que em alguns momentos são costurados para garantir o sentido de unidade para a trama, outra questão importante a ser apontada é que no filme não há muito aprofundamento sobre a vida dos personagens, ou seja, não sabemos muito sobre suas origens, contexto social, caráter ou outros aspectos que possam contribuir com algumas possibilidades de análise, as informações que temos são rasas, mas ao mesmo tempo as condições corporais são bem explícitas. Talvez a proposta dos autores do filme seja que o espectador possa refletir e deduzir sobre as demais características dos personagens, nos levando a compreender que apesar das diferenças corporais, são pessoas que tentam viver suas vidas da melhor maneira possível.

A primeira cena do filme se passa no ano de 2000 , começa com uma ligação de Morris, homem aparentando uns 40 anos, ele está numa sala toda cor de rosa e falando ao telefone recebe informações sobre o nascimento de seu filho. Logo na sequência uma voz feminina corta a ligação e pergunta se ele já havia terminado. É uma senhora, já mais de 50 anos, ela está quase toda nua e parece ser a dona de um estabelecimento de prostituição.

Na mesa está um álbum também cor de rosa com escrito na capa "niños". Ela começa a abrir o álbum e mostra fotografias de crianças, ao ver a tensão de Morris a cafetina então lhe mostra outro álbum com título de "malformados". Aparentemente, ao entender as preferências e necessidades do cliente por crianças, lhe é apresentado o álbum de Laura, uma menina de 11 anos com uma malformação muito peculiar, ela não possui olhos.

$\mathrm{Na}$ fala retórica da senhora podemos destacar questões que permeiam o universo da perversidade/barbárie humana. Uma das falas é: 
"No puedes controlar sus instintos, lo que pasa ahora te pasará por toda la

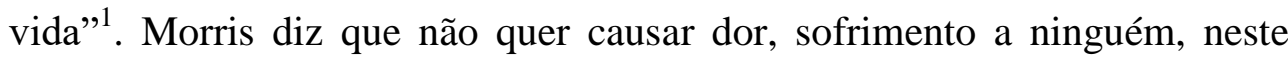
momento ela diz que tem gente que nasce para sofrer, no caso pessoas como Laura, desta forma não faz diferença quem causará tal sofrimento. Em tom de conclusão da conversa a proxeneta fala: "El mundo es horrible, el humano es horrible, pero no podemos huir de él, porque nosotros somos el horror hay que aceptarlo",

A próxima personagem a aparecer nessa sequência é Laura, a qual Morris escolheu para realizar seu fetiche/desejo sexual. Ela tem uma pele que cobre as cavidades orbitais, o lugar onde estariam os olhos, a menina usa um vestido rosa, assim como todo o cenário também é composto pela cor rosa ou tons de rosa. Laura canta a canção "Alguien cantó”, de Matt Moron, que parece dialogar com o momento, misto entre melancólico e angustiante, além de fazer referência ao não poder ver. Ao final da sequência Morris dá a ela um par de diamantes rosa, que serão usados por ela sobre a pele onde estariam seus olhos a partir de então.

As próximas cenas se passam no ano de 2017. E quem aparece é Samantha, uma mulher que tem por volta dos 25 a 30 anos, ela possui também uma má formação física, ou seja, tem o aparelho ou sistema digestivo invertido, no lugar da boca está o ânus e vice-versa. Ela vive praticamente reclusa sob a proteção do pai, que parece controlar suas saídas em público. Na primeira cena ela tira uma selfie e a publica no instagran, porém momentos depois a publicação é censurada e cancelada. $\mathrm{Na}$ sequência ela vai a uma lanchonete e a garçonete ri dela. Na saída dessa lanchonete dois homens a assediam. Numa segunda oportunidade que eles a encontram na saída da mesma lanchonete tentam violentá-la, ela foge assustada e em choque acaba atropelando Cristian que é outro personagem da trama.

\footnotetext{
1 "Não podes controlar seus instintos, o que sente agora sentirá por toda a vida" Tradução nossa.

2 "O mundo é horrível, o ser humano é horrível, mas não podemos fugir dele, porque nós somos o horror e temos que aceitar isso" Tradução nossa.
}

Filos. e Educ., Campinas, SP, v.11, n.1, p. 36-61, jan./abr. 2019 - ISSN 1984-9605 
Cristian é um jovem que sofre de disforia corporal, ele não aceita a existência de suas pernas e faz mutilações na tentativa de amputá-las. O personagem tem uma relação difícil com a mãe, que o culpa pelo sumiço do marido. Na tentativa de tratar o problema da disforia a mãe o leva para uma consulta psicológica, na qual ocorre o atendimento conjunto da mãe e filho, mas o processo gera discussão e Cristian foge. Após a fuga se esconde entre duas grandes lixeiras, observa que um carro vindo para aquela direção e se deita deixando as pernas expostas, a motorista desatenta passa por cima das pernas e as imagens levam a entender que foram amputadas. Em quadros posteriores é noticiada a morte do personagem Cristian e também o seu velório, no qual fica evidenciado que ele gostaria de ter uma calda de sereia no lugar de pernas. A única referência do pai era uma tatuagem de sereia. Ao final descobriremos que ele era o filho de Morris. Portanto, uma relação bem conturbada e complexa desta família.

A garçonete da lanchonete frequentada por Samantha também é personagem com corpo fora dos padrões considerados normais, ela é obesa. A personagem tem o mesmo nome da atriz Itziar, o que nos leva a entender que pode haver uma relação autobiográfica entre ambas. Essa personagem gasta quase todo o dinheiro que ganha para estar com Laura, porque com ela (que não vê) não há possibilidade de ser rejeitada.

Outra personagem é Vanessa, uma mulher com acondroplasia, uma mutação genética, que provoca um tipo de nanismo. Ela trabalha na televisão e interpreta um personagem que é um ursinho, veste essa fantasia de urso todos dias, é explorada por seu empresário por conta de sua baixa estatura. Porém, cansada desta vida de exploração e de solidão, decide fazer uma fertilização in vitro, ao constatar a gravidez ela tenta abandonar o trabalho na TV para se dedicar à maternidade, pois é uma gravidez de risco.

O próximo personagem é Ernesto, um homem fisicamente "normal", ele é apaixonado por Ana, uma mulher que tem o rosto deformado. Mas Ana não ama Ernesto, ela ama Guille, um homem que tem a cabeça e o rosto deformado por queimaduras. 
Nesse quase triangulo amoroso são apresentadas questões importantes sobre a concepção de normalidade. Guille deseja voltar a ter seu rosto de antes, a ter uma aparência "normal", o que o afasta de Ana, pois para ela a sua deformidade é "normal", ou seja, é o seu modo de ser e estar no mudo. Ela é o seu próprio padrão. Porém algo inusitado ocorre, ele encontra uma maleta de dinheiro e decide então submeter-se a cirurgias plásticas para reconstruir seu rosto, portanto, decide pela tentativa de readequação ao padrão considerado normal. Já Ana rompe com Guille e segue sozinha, pois não aceita nem a concepção de Guille de voltar aos padrões da presumida normalidade e nem a de Ernesto que se apaixonou por ela por conta de sua "não normalidade", conforme as próprias palavras do personagem Ernesto no quadro em que conversa com Ana "no me gustan las mujeres normales"3.

Nesse ínterim, depois que Ana dispensou Ernesto, ele encontra Samantha e se apaixona por ela, sendo que ao final do filme os dois estão morando na mesma casa junto com o pai dela e a cena que encerra esse quadro é o beijo do casal.

Quanto aos demais personagens vemos a garçonete Itziar e Laura estão juntas na lanchonete e aparentemente felizes. Ana seguiu sozinha a sua vida. Vanessa realiza o parto e a desejada maternidade. Guille aparece recuperando-se da cirurgia plástica.

Em Pieles o corpo deforme ou anômalo é sempre evidenciado. Num primeiro momento chega a ser impactante ver os corpos deformados, anômalos ou deficientes, em geral corpos diferentes daqueles padronizados e considerados normais. A partir dessa reação de impacto e desconforto é que nos motivamos a analisar os conceitos de corpo, de normalidade e anormalidade. Para tal empreitada buscaremos estabelecer diálogos com teóricos e conceitos da contemporaneidade que abordam essas temáticas ou questões em seus estudos.

\footnotetext{
3 “Não gosto das mulheres normais”. Tradução nossa.
} 


\section{Corpo "normal" e corpo periférico como construção histórico-} social

Começaremos por um aporte teórico que nos subsidie em discussões sobre conceitos de corpo, principalmente a partir da modernidade até os dias contemporâneos.

De acordo com o enredo, temas e personagens descritos acima sobre o filme daremos mais enfoque sobre o corpo como construção históricosocial de acordo com a cultura ocidental ou ocidentalizada. Ressaltamos que muitas vezes abordaremos o termo corpo como sinônimo de "sujeito" atravessado pelos discursos: ideológico, cultural, social, político, de gênero, étnico, de classe, etc. Porém, para esta análise, como já apresentado anteriormente, nos deteremos mais aos conceitos de normalidade $\mathrm{e}$ anormalidade, com base nos corpos (brancos e cisgêneros) disformes e/ou anômalos.

É importante destacar que conceito sobre o corpo apenas como elemento de natureza biológica não sustentaria as nossas argumentações a respeito de corpos por vezes marginalizados e rechaçados do convívio social por serem fisicamente diferentes. Sendo assim, buscamos ir além da condição natural e biológica, buscamos problematizar ideais de corpo que são construídos pelas lentes da cultura hegemônica.

Para Rocha e Rodrigues (2013, p. 16) "Cada cultura 'modela' ou 'fabrica' à sua maneira um corpo humano. Toda sociedade se preocupa em imprimir no corpo, fisicamente, determinadas transformações, mediante as quais o cultural se inscreve e se grava sobre o biológico”. Portanto, os corpos podem sofrer mudanças, variações e atribuição de valores diferentes de acordo com os contextos históricos e culturais que são submetidos, entendemos que esta construção histórico-social e cultural do corpo também pode ser vista pelos olhares da semiótica.

De acordo com Bártolo (2007, p. 195) o corpo em sua "experiência funcional (o seu uso para trabalhar, para dormir, para comer, para copular etc.)" e em sua “experiência social etc - é, ela própria determinada por uma semiótica do corpo que é imposta a partir de fora e que é, progressivamente, 
afirmada pela família, na escola, na igreja, na fábrica". Complementarmente vemos em Rocha e Rodrigues (2013, p. 16):

Enfim, não há sociedade que não fira semioticamente o corpo de seus membros, cada uma se especializando na geração de determinados corpos: na produção daqueles corpos que servirão como insígnias da identidade grupal, nas quais a substância biológica trabalhará como matéria sociológica.

Ao pensar o corpo como um constructo histórico-social o contextualizaremos após o fim do período feudal e a partir era moderna, com o surgimento da burguesia e futuramente do sistema capitalista em que ele passa a ser normatizado pelos valores e ideais dessa era e sistema. Segundo Rocha e Rodrigues (2013, p. 32) após a emancipação da submissão do poder feudal "os burgueses vão tomando posse de seus próprios corpos. Posteriormente farão o mesmo com os corpos alheios". De acordo com os autores este modelo se reproduzirá por volta do século XVIII, tendo como “protagonistas artesãos que farão florescer multidões de pequenas empresas individuais-familiares, nas quais o mais fundamental dos meios de produção será o corpo".

Este foi um primeiro episódio, historicamente fundamental: a conquista do corpo e sua transformação em propriedade individual e privada de burgueses e poderosos. Um corpoprodutor, corpo-instrumento, de que os burgueses são os primeiros sujeitos. Corpo a ser treinado, disciplinado, alimentado, fortificado, conhecido. Corpo que deve rentabilizar, frutificar. É também o corpo a que os dominados deverão ser subjugados: corpo-ferramenta, corpo-alienado, corpo que se troca por um salário. (Rocha e Rodrigues, 2013, p. 32)

Ainda para os mesmos autores o corpo na era moderna passa por um “segundo ato”. É o do “corpo-meio-de-produção", que por sua incapacidade de atender integralmente às ambições do sistema capitalista acaba sendo desprezado e substituído por máquinas. "O corpo se esgota relativamente cedo como ferramenta adequada à expansão máxima da economia: o sistema se torna industrial, o que significa fundamentalmente substituição 
do transpirar de músculos pelo trabalho de máquinas". (Rocha; Rodrigues, 2013, p.33)

Mas para que esse corpo "livre" desempenhe seu papel de maneira servil, foi preciso criar mecanismos de docilidade. A respeito disto citamos Foucault (1987, p. 163) que nos diz "que o corpo é objeto de investimentos tão imperiosos e urgentes; em qualquer sociedade, o corpo está preso no interior de poderes muito apertados, que lhe impõem limitações, proibições ou obrigações".

Foucault também apresenta em sua argumentação que esse sistema de controle do e sobre o corpo não se tratava de cuidado com ele, “[...], mas de trabalhá-lo detalhadamente; de exercer sobre ele uma coerção sem folga, de mantê-lo ao nível mesmo da mecânica - movimentos, gestos atitude, rapidez: poder infinitesimal sobre o corpo ativo". (Foucault, 1987, p. 163). Ainda sobre processos e métodos de sujeição, de controle e docilidade do corpo Foucault nos diz que isso foi possível graças ao que ele nomeia como "disciplinas".

O corpo humano entra numa maquinaria de poder que o esquadrinha, o desarticula e o recompõe. Uma "anatomia política", que é também igualmente uma "mecânica do poder", está nascendo; ela define como se pode ter domínio sobre o corpo dos outros, não simplesmente para que façam o que se quer, mas para que operem como se quer, com as técnicas, segundo a rapidez e a eficácia que se determina. A disciplina fabrica assim corpos submissos e exercitados, corpos "dóceis". A disciplina aumenta as forças do corpo (em termos econômicos de utilidade) e diminui essas mesmas forças (em termos políticos de obediência). (Foucault, 1987, p. 164-165)

Retomando os pressupostos de Rocha e Rodrigues (2013. p. 33) diante da insatisfação do sistema produtivo, ao ser substituído pela máquina o corpo poderá obter uma "liberação", ou seja, ele “[...] deverá progressivamente sair das fábricas. [...] não é mais o corpo-ferramenta que ocupará o proscênio". E que numa "civilização de abundância industrial, de

\footnotetext{
4 “O momento histórico das disciplinas é o momento em que nasce uma arte do corpo humano, que visa não unicamente o aumento de suas habilidades, nem tampouco aprofundar sua sujeição, mas a formação de uma relação que no mesmo mecanismo o torna tanto mais obediente quanto é mais útil, e inversamente". (Foucault, 1987, p. 164)
} 
lazer e consumo, o corpo terá, doravante, nova tarefa: a de ser o suporte material e ideológico da produção". Podemos inferir dessa afirmação que o corpo burguês avança de seu estágio de "corpo-ferramenta" para mais um estágio que é de corpo como consumo. Emerge então um corpo "elitizado", segundo os autores "o novo corpo, agora plenamente 'livre', estetizado, vestido, curtido, ginasticado, medicalizado, indo e vindo; [...] Um corpo destinado às férias e às horas livres, voltado para o lazer, o prazer e o gozo. Um corpo belo e liso, sem calos nem cicatrizes". (Rocha; Rodrigues, 2013, P. 35).

Entendemos que nas últimas décadas as concepções e ideais de corpo têm caminhado para universo do eu, para o individual, mesmo assim, de maneira geral, não há um rompimento com os valores e modelos de corpo social construído ao longo da história e das dinâmicas culturais que se relaciona num coletivo, em grupos, culturas, etc.

Segundo Fernandes e Barbosa (2016) para alguns analistas esse evento do corpo como constructo individual tem conquistado novo protagonismo no cenário contemporâneo que seria o chamado "hiperindividualismo contemporâneo".

Os processos referenciados acima não fazem com que os regimes de normatividade do corpo desapareçam, pois eles ainda seguem nesta interface entre o indivíduo e o social.

Ao tratarem da construção social dos corpos periféricos Fernandes e Barbosa (2016) nos apresentam o termo "centralidade corpórea”, de acordo eles o termo pode ser entendido como "o resultado da valorização de determinados aspetos do corpo, que passam a ser tomados como modelo do que este deve ser”. (Fernandes e Barbosa, 2016, p. 70).

As argumentações feitas pelos autores dialogam muito bem com nossa análise proposta sobre filme Pieles, pois como descrito anteriormente sobre os personagens do filme podemos identificar em alguns as "corporalidades que se afastam da centralidade corpórea", que fogem da norma ou do padrão social de corporalidade, de como os corpos deveriam ser. Fernandes e Barbosa (2016, p. 70) tratam: 
[...] a noção de corpo periférico como aquele do qual emanam signos desvalorizados pelos padrões constituintes da centralidade corpórea. Exemplificamos com as deformidades físicas e com a obesidade, analisando a partir delas como pode o corpo constituir-se como fonte de estigma e locus de sofrimento psicológico nos processos interativos correntes.

Ao se pensar em corpos lidos e tidos como periféricos por apresentarem diferenças anatômicas em relação àqueles postos como modelos ou padrões, corroboramos com a concepção de Fernandes e Barbosa (2016) de que "há uma ordem corporal - e desvios a essa ordem. A ordem corporal inicia e revela a ordem social". De acordo com referidos autores a escola, além da família, seria um dos lugares iniciais de imposição dessa ordem corporal e como vimos em Foucault os mecanismos de controle do corpo e da condição de docilidade, as disciplinas.

Retomando a discussão do corpo, mas agora a serviço de uma ordem social de consumo, o foco do controle e das normas também tendem a sofrer mudanças, para Fernandes e Barbosa (2016, p. 76)

A disciplina sobre o corpo é agora ditada não pela sua utilidade e docilidade, mas pela sua estética, nas sociedades que passaram a privilegiar a imagem e o aparecer - as sociedades do complexo de Narciso, como as designou Lash (1991). É, ainda, uma disciplina que testemunha a persistência e o sacrifício envolvidos no treino físico e no rigor das dietas $[\ldots] ”$.

E acrescentamos que as diversas formas de intervenções cirúrgicas, bem como o uso de substâncias químicas de forma lícita e/ou ilícita, como forma de produzir o corpo idealizado conforme os padrões contemporâneos, são utilizados cada vez mais cotidianamente. Nesse sentido, ratificamos a concepção apontada por Fernandes e Barbosa (2016, p. 74-75)

As novas tecnologias de produção em massa desencadearam um processo de homogeneização de gestos e hábitos que se 
estendeu a outras esferas sociais, entre elas a educação do corpo, que passou a se identificar não só com as técnicas, mas também com os interesses da produção (Hobsbawm, 1996 apud Pelegrini, 2006). Assim, o ser humano é colocado a serviço da economia e da produção, gerando um corpo produtor que, portanto, precisa ter saúde para melhor produzir e precisa de adaptar-se aos padrões de beleza para melhor consumir.

Fernandes e Barbosa nos diz que a corporalidade central além de seu caráter normativo também se apresenta como produtora de constrangimentos, do que deveria ser a corporalidade na esfera do social, também destacam três forças que contribuem na produção desse efeito. Para elucidar melhor essa questão os autores nomearam metaforicamente estas três forças ${ }^{5}$ como: “à marquesa do consultório", "à passerelle dos desfiles

5 Corpo na marquesa seria a medicina preventiva, a promoção dos estilos de vida saudáveis, os rastreios populacionais das patologias mais endémicas, as dietas saudáveis; o desenvolvimento das disciplinas do campo da saúde, com a grande expansão da oferta formativa de novas profissões (nutricionismo, diferenciação de múltiplos técnicos de diagnóstico e de reabilitação), mostra como a normatividade do corpo surge já não por contraste com a doença, mas como vontade de manutenção da saúde e como possibilidade de antecipação dos estados mórbidos de modo a controlar o risco do seu desencadeamento. [...] Corpo na passerelle: o dos protagonismos e das aparições, de que a moda ou as vernissages sociais são a cúpula. [...] o final do XX e o atual são os séculos da imagem. Mas a característica da imagem é ser virtual, e a omnipresença do corpo na exibição da imagem é, portanto, a afirmação do corpo virtual. O corpo virtual não é o corpo, mas algo melhor do que ele: parte dele, mas melhora-o [...]. A vulgarização do photoshop é o exemplo acabado: o corpo passerelle enquanto ícone de onde irradia o corpo central não é o da aproximação aos corpos reais, mas o da sua mitificação enquanto objeto feito para o deslumbramento. Corpo no podium: numa sociedade que glorifica a competição, o corpo tem lugar de destaque quando aparece no podium. As olimpíadas da época moderna surgem nos finais do século XIX para celebrar este corpo que triunfa e aparece no seu esplendor. São signos da importância dada ao corpo no podium as piscinas, os ginásios, a proliferação de lugares das mais variadas modalidades de práticas desportivas, os personal trainers [...] (Fernandes e Barbosa, 2016, p.75-76) 
de moda" e o "podium das competições desportivas". E para eles é na "distância dos corpos reais aos ideais exibidos na passerelle é justamente o espaço onde podem inscrever-se as periferias”. (Fernandes e Barbosa, 2016, p.76).

Os autores novamente apontam o corpo periférico como aquele que seria visto muitas vezes como abjeto, ou seja, o "das secreções, dos cheiros, dos ruídos - tudo quanto a educação do indivíduo civilizado, que se afasta decisivamente da barbárie [...]”. (Fernandes e Barbosa, 2016)

Corpos deformados ou "anormais" perturbam o sistema e suas ordens, eles incomodam, como já apontamos anteriormente, seja por sua antiestética ou por apenas coexistirem em lugares que não lhes seriam próprios, como os espaços públicos e de convívio social. A sua existência se daria entre a lei e a disciplina. Por isso muitas vezes sofrem com a processos exclusão ou de reclusão.

[...] o corpo periférico é também aquele que tapamos porque foge da geometria da beleza, da esquadria da desenvoltura física. O traje é esta produção que impede o corpo de se expor à evidência da sua imperfeição, sujeitando o seu portador ao risco da periferização. [...]. As deformidades do corpo, inscritas à nascença ou adquiridas no trajeto existencial, são a mais evidente fonte de periferização [...].

Sobre o corpo como capital simbólico e elemento importante nas relações de poder entre grupos sociais, étnicos etc., Fernandes e Barbosa (2016) citam Bourdieu (1979) ao apontar que as propriedades corporais podem funcionar como capital para a obtenção de lucros sociais, para conceder à representação dominante do corpo um reconhecimento incondicional, os corpos periféricos são os excluídos ou marginalizados desse capital. E encontramos em Platt (2014, p. 48) algumas assertivas que vão ao encontro das ponderações acima

Ao concebê-lo deficiente/“diferente"/anormal (pejorativamente; num sentido negativo), atesta-se sua "incompetência" em gerenciar sua vida e assumir um papel 
social no "mundo da produção", pois não deteria consigo os qualitativos suficientes para isso - não teria a sua disposição todos os mecanismos físico-psíquico-intelectual e social para desenvolver-se em sociedade. Compreende-se, aqui, que este indivíduo sempre se encontraria à periferia da razão social.

Existem corpos deficientes ou que possuem anomalias que podem ser considerados mais aceitáveis, de acordo com os padrões de corporalidade central, principalmente aquelas que são menos evidenciadas ou facilmente camufladas. Portanto, podemos identificar fissuras na centralidade corpórea, pois ela não consegue inculcar totalmente os seus ideais padronizadores.

A seguir traremos mais elementos que dialogam com que já apresentamos até aqui, sob o prisma do binômio normalidade/anormalidade, o qual é perpassado pelos discursos biomédico, científico, do direito, entre outros.

\section{O normal e o anormal}

Em Pieles os termos ou temas como normalidade e anormalidade são destaques, ao trazer personagens com corpos disformes, anomalias congênitas ou não, acaba levando o espectador a reflexões sobre tais termos ou conceitos e nos aduz a algumas questões como: Como é ser normal ou anormal? Eu sou normal? E o outro? Se sou diferente do que é considerado normal, serei anormal?

No filme quase todos os personagens apresentam diferenças físicas que comumente classificamos por anomalia ou deficiência, por conseguinte anormais. É bom destacar que não trataremos aqui de diferenças étnicoraciais, nem culturais ou de gênero e sexualidade. As diferenças corpóreas a que nos referimos são as de cunho físico-biológico, sejam elas deformações, anomalias, etc. e como estas diferenças interferem nas histórias de vida destes personagens.

$\begin{array}{ccccccc}\text { Citamos } & \text { Platt } & (2014) & \text { em } & \text { seu } & \text { trabalho } & \text { sobre } \\ \text { normalidade/anormalidade, } & \text { ao } & \text { tratar } & \text { sobre } & \text { adequação } & \text { social } & \text { busca }\end{array}$


apresentar a construção dos conceitos a partir de três concepções na vida humana. A primeira é a da anátomo-fisiológica que destaca a relação da funcionalidade dos órgãos e membros corporais disponíveis nos seres humanos. Esta visão resultaria muito mais de suas possibilidades físicas, corporais, ou seja, teriam sua otimização na resposta corporal adequada, em que cada órgão desempenharia sua função, classificando assim os indivíduos como "normais ou anormais segundo o número de respostas adequadas em conformidade com o arbitrário social destas funções. A resposta incompleta ou inadequada seria um indício de que o indivíduo é/está inapto à função”. (Platt, 2014, p. 29)

Já a segunda esfera é a do psicossocial ou dos estudos voltados à Psicologia Social, que se detêm na representação social, nos papéis sociais, nos processos de identificação e nas construções simbólicas. De acordo com a autora seria "entender o fenômeno da subjetivação, organizando e determinando as objetivações no espaço social", apontando as influencias histórico-sociais que os sujeitos recebem antes e após nascerem, portanto, os padrões, modelos de vida social entendidos como adequados ditarão o conceito de normal e anormal.

E a terceira concepção é a histórico-social que, de acordo com Platt, é impossível margear a discussão sobre a normalidade/anormalidade sem abordar o que representativamente foi se construindo socialmente. Portanto, conforme Platt, a idealização do que é normal/anormal não tem a possibilidade de ser respondida a partir de conceitos auferidos aos indivíduos, quer seja por seu aspecto físico ou pela não completude às atividades que lhes estão postas a desempenhar. Para Platt (2014, p. 29) "somente na revisitação dos aportes que deliberam sobre o processo de humanização do indivíduo (leia-se a partir da categoria trabalho), é que se pode entender o mundo das representações definidas em sociedade".

A autora atenta-se em discorrer muito mais sobre a concepção histórico-social na construção e manutenção dos conceitos de normalidade/anormalidade, assim como já apresentamos anteriormente sobre os conceitos e ideais ocidentais de corpo como sendo também muito mais influenciados pelas questões histórico-sociais. Esse binômio na 
modernidade vai se estabelecer e ser regulado pelo prisma da produtividade, de utilidade, de eficiência, entre outras.

Neste ponto, ao reconhecermos os mecanismos que objetivamente reduzem os indivíduos aos limites constantes daquilo que ontologicamente os define enquanto humanos - o trabalho e as relações de trabalho -, alienando-os deste processo, e assim termos condições de acessar os dados que modificam objetivamente o processo de humanização do homem, perpassaremos sobre os resultados desta barbárie sem fim, a partir do processo que sempre esteve pari passu com a questão da normalidade/anormalidade: o processo da saúde/doença nos indivíduos. (Platt, 2014, p. 41).

Destarte, "àquele que "destoa" de tais parâmetros, resta apenas o ostracismo (ser um pária social), uma vez que a diferença é significativa enquanto 'desencaixe' ao estabelecido" (Platt, 2014, p. 40). Logo, os corpos destoantes da norma ou do que é posto como corporalidade central tendem a ser considerados como excluídos e periféricos.

Canguilhem (2009) nos apresenta em seus estudos sobre o normal e o patológico, elementos para entendermos mais a respeito das origens etimológicas dos termos normalidade e anormalidade, que parte do seu lugar de formação que é a medicina. Vejamos as definições de normalidade.

O Dictionnaire de médecine de Littré e Robin define o normal do seguinte modo: normal (normalis, de norma, regra), que é conforme à regra, regular. O Vocabulaire technique et critique de la philosophie de Lalande é mais explícito: é normal, etimologicamente — já que norma significa esquadro —, aquilo que não se inclina nem para a esquerda nem para a direita, portanto o que se conserva em um justo meio-termo; daí derivam dois sentidos: é normal aquilo que é como deve ser; e é normal, no sentido mais usual da palavra, o que se encontra na maior parte dos casos de uma espécie determinada ou o que constitui a média ou o módulo de uma característica mensurável. (Canguilhem, 2009, p. 48).

A citação acima dialoga com as argumentações sobre corporalidade central e construção social do corpo como sendo normatizadas por vários organismos e mecanismos culturais e sociais, como um padrão a ser seguido. A partir dessas definições façamos a seguinte reflexão sobre a anormalidade: se você não está de acordo com os critérios ou normas 
estabelecidas por convenções socioculturais, políticas, econômicas ou por imposições midiáticas, então você é anormal? Logo, ser diferente daquilo que se deveria ser, pode levá-lo a ser classificado como anormal.

É importante destacar que Canguilhem (2009) busca romper com as distorções destes conceitos propostas pela tese médico-biológica, principalmente o de anormalidade, buscando também desassociar relações intrínsecas entre anormal e patológico. Ele destaca que estudos do normal e do patológico na medicina, ao investigar as doenças, buscavam respostas e as causas para reestabelecer o estado normal do corpo, a partir desse momento começa-se a pensar sobre o normal e o patológico. Com isso, nos traz a premissa de que "dominar a doença é conhecer suas relações com o estado normal que o homem vivo deseja restaurar, já que ama a vida. Daí a necessidade teórica, mas com prazo técnico diferido, de fundar uma patologia científica ligando-a à fisiologia”. (Canguilhem, 2009, p. 13).

As discussões de normalidade, portanto, são trazidas a partir dos estudos médicos sobre como as doenças ou patologias produziam mudanças ou ações nos corpos que antes estavam no seu estado de saúde ou de “normalidade". Na argumentação de Canguilhem compreendemos que ele parece nos dizer que a doença é processo normal na vida humana.

A natureza (physis), tanto no homem como fora dele, é harmonia e equilíbrio. A perturbação desse equilíbrio, dessa harmonia, é a doença. Nesse caso, a doença não está em alguma parte do homem. Está em todo o homem e é toda dele. [...] A doença não é somente desequilíbrio ou desarmonia; ela é também, e talvez sobretudo, o esforço que a natureza exerce no homem para obter um novo equilíbrio. A doença é uma reação generalizada com intenção de cura. O organismo desenvolve uma doença para se curar. (Canguilhem, 2009, p. 12).

E estes conceitos amplamente difundidos pela medicina que geraram no imaginário cultural e social ocidental os discursos que fortemente associam as diferenças, principalmente no campo da corporalidade, com corpos doentes, às anomalias, às aberrações, aos monstros e termos afins. Canguilhem traz para reflexão que a doença não é senão outra coisa que o normal, que todos os corpos lidam naturalmente com ela como processo habitual da condição humana e restauração do equilíbrio. 
Os corpos que apresentam anomalias, mutações ou corpos deficientes tendem a ser considerados pelo senso comum como corpos doentes, ou seja, existe uma associação direta entre anomalias, mutações ou corpos deficientes e patologias. Quem nunca ouviu quer que seja dizer a uma gestante, até mesmo ela própria, que o bebê venha "normal" e com saúde. Logo, para o senso comum ser "normal” é ter saúde, ou vice-versa. Sendo assim, se a criança não nascer "normal", será anormal e, portanto, não será saudável. Pessoas consideradas "normais" muitas vezes em atitudes de ignorância e preconceitos evitam frequentar os mesmos espaços, sentar em lugares ou até utilizar utensílios/objetos que pessoas disformes ou deficientes. Quem realmente está enfermo?

Canguilhem também apresenta uma ideia de como os termos anormal e a anomalia começaram a ser empregados como correspondentes. O autor cita o "Vocabulaire de Lalande" para explicar segundo eles os equívocos ou confusão etimológica que contribuíram para essa aproximação de anomalia e anormal.

Anomalia vem do grego anomalia, que significa desigualdade, aspereza; omalos designa, em grego, o que é uniforme, regular, liso; de modo que anomalia é, etimologicamente, anomalos, o que é desigual, rugoso, irregular, no sentido que se dá a essas palavras, ao falar de um terreno. Ora, freqüentemente houve enganos a respeito da etimologia do termo anomalia derivando-o não de orna-los, mas de nomos, que significa lei, segundo a composição a-nomos. Esse erro de etimologia encontra-se, precisamente, no Dictionnaire de médecine de Littré e Robin. Ora, o nomos grego e o norma latino têm sentidos vizinhos, lei e regra tendem a se confundir. Assim, com todo o rigor semântico, anomalia designa um fato, é um termo descritivo, ao passo que anormal implica referência a um valor, é um termo apreciativo, normativo, mas a troca de processos gramaticais corretos acarretou uma colusão dos sentidos respectivos de anomalia e de anormal. Anormal tornouse um conceito descritivo, e anomalia tornou-se um conceito normativo. (Canguilhem, 2009, p. 50-51).

O mesmo autor (2009, p, 51) continua com a argumentação que a “anomalia é um fato biológico e deve ser tratada como fato que a ciência natural deve explicar, e não apreciar". E "na anatomia, o termo anomalia deve conservar estritamente seu sentido de insólito, de inabitual; ser 
anormal consiste em se afastar, por sua própria organização, da grande maioria dos seres com os quais se deve ser comparado".

Porém esses conceitos, com ou sem equívocos, saem de suas esferas e chegam ao senso comum como já dissemos anteriormente, de acordo com Foracchi e Martins (1977, p. 24 apud Platt, 2014)

a anomalia partiria, na percepção de nosso senso comum, de um volume de pré-conceitos; ou seja, descrevemos como anômalo o que não é "normal", e o normal seria todo o conjunto de ordenamentos éticos e contínuos de controle social, cuja violência, simbólica ou não, enquadra os seres humanos em suas diferenças individuais ou grupais e conforme a perspectiva classista dominante, que determina o "consenso compulsório".

Outro termo que se alinha de maneira pejorativa ao termo de anomalia é o de monstruosidade. Canguilhem (2009) cita I. Geoffroy SaintHilaire da área médica que se declara a favor de sua distinção, apresentando quatro divisões ou tipos de anomalias, são elas: variedades, vícios de conformação, heterotaxias e monstruosidades.

A primeira são anomalias simples, leves, que não colocam obstáculo à realização de nenhuma função e que não produzem deformidade; já a segunda são anomalias também simples, pouco graves do ponto de vista anatômico, e que tornam impossível a realização de uma ou várias funções ou produzem uma deformidade; por exemplo, a imperfuração do ânus, o lábio leporino; a terceira são anomalias complexas, aparentemente graves do ponto de vista anatômico, mas que não impedem nenhuma função e não são aparentes externamente; o exemplo mais notável, apesar de raro, transposição completa das vísceras, ou situs inversus e as Monstruosidades são anomalias muito complexas, muito graves, que tornam impossível ou difícil a realização de uma ou de várias funções, ou produzem, nos indivíduos por elas afetados, uma conformação muito diferente da que sua espécie geralmente apresenta, por exemplo, a ectromelia ou a ciclopia.

Ao apresentarmos as categorias das anomalias acima podemos dizer que se elas não afetam ao funcionamento e nem aos desempenhos satisfatórios dos órgãos do corpo humano, então não há nada de anormal nesse corpo, pois ele se mantém apto para viver, e principalmente para 
realizar funções sociais. No filme Pieles cuja tradução é pele, um dos maiores órgãos do corpo humano, são expostas anomalias e deformações que estão nítidas e que dificilmente podem ser camufladas, talvez por isso nos choca, nos impacta a exposição explícita destas diferenças, destes corpos destoantes.

Como apontamos anteriormente a respeito do corpo existem algumas deformidades, mutações e deficiências que podem ser consideradas mais aceitáveis para o convívio social, ou seja, para a inclusão destes sujeitos, principalmente aquelas que visivelmente ou esteticamente quase não são percebidas. Já no caso daqueles corpos considerados como aberrações ou monstros essa aceitação não é possível, pois os graus de anomalias são explícitos.

Foucault (2001) apresenta em seu texto "Os anormais" duas categorias de monstros, a primeira é o da deformidade, da enfermidade, do defeito ou disforme, o enfermo e o defeituoso, e outra daquilo que não tem forma humana, como os monstros das histórias míticas. Ele também faz algumas considerações entre anomalia e monstruosidade. Em sua retórica diz que a noção de "monstro humano" é "jurídico-biológico", ou seja, “essencialmente uma noção jurídica - jurídica, claro, no sentido lato do termo, pois o que define o monstro e o fato de que ele constitui, em sua existência mesma e em sua forma, não apenas uma violação das leis da sociedade, mas uma violação das leis da natureza [...] ao mesmo tempo que viola a lei, ele a deixa sem voz". (Foucault, 2001, p. 69-70).

Em conclusão a esta parte, para Canguilhem o anormal não é o patológico, pois este implica "pathos, sentimento direto e concreto de sofrimento e de impotência, sentimento de vida contrariada", porém o patológico é realmente o anormal. Ele também destaca que a anomalia e a mutação não são, em si mesmas, patológicas, mas sim outras normas de vida possíveis. ${ }^{6}$

6 Se essas normas forem inferiores — quanto à estabilidade, à fecundidade e à variabilidade da vida — às normas específicas anteriores, serão chamadas patológicas. Se,

Filos. e Educ., Campinas, SP, v.11, n.1, p. 36-61, jan./abr. 2019 - ISSN 1984-9605 


\section{Corpos periféricos, normal e anormal no filme Pieles}

Os corpos dos personagens do filme Pieles representam bem a argumentação que trouxemos sobre corporalidade central e corpos periféricos, pois os corpos de alguns personagens podem ser considerados como periféricos, não só aqueles que apresentam deformações e/ou anomalias, mas também o da obesidade, como é caso da garçonete Itziar, que mesmo não apresentando alterações ou modificações físicas congênitas ou por algum acidente, também é um corpo que sofre certo tipo de reclusão, um corpo que normalmente não é desejado e nem atraente, um corpo que incomoda por não atender aos padrões da corporalidade central, por ser lido como corpo não saudável e principalmente por distanciar-se esteticamente do padrão de corpo considerado desejável.

Para ilustrar a nossa argumentação discutida a partir da conceituação de normal e anormal, apresentamos um trecho da crítica feita por Bruno Carmelo no site Adoro Cinema, o título do texto é "Pieles a casa de bonecas deformadas", de acordo com o crítico o filme trata-se de

[...] uma comédia dramática espanhola intercalando esquetes sobre pessoas com deformidades físicas. Os casos retratados vão desde condições reais (nanismo, obesidade mórbida, queimaduras) a patologias imaginárias (uma personagem com uma pele cobrindo os olhos, outra com o ânus no lugar da boca).

Vejamos que o próprio crítico coloca as anomalias ou as malformações apresentadas no filme como sendo patologias, e, talvez de acordo com sua ideia de realidade e normalidade ele entenda que tais anomalias mais complexas só são possíveis no campo do imaginário, como os dos monstros mitológicos. Portanto, salientamos que, a partir desses indícios, há imbricações entre anomalias e anormalidades no âmbito do

eventualmente, se revelarem equivalentes - no mesmo meio — ou superiores - em outro meio - , serão chamadas normais. Sua normalidade advirá de sua normatividade. O patológico não é a ausência de norma biológica, é uma norma diferente, mas comparativamente repelida pela vida. (Canguilhem, 2009, p. 56).

Filos. e Educ., Campinas, SP, v.11, n.1, p. 36-61, jan./abr. 2019 - ISSN 1984-9605 
senso comum, seja como for o efeito para tais pessoas classificadas como disformes, anômalas e na sequência como anormais é inequívoco.

Ao assistir o filme nos deparamos com uma agenciadora de corpos periféricos, corpos disformes. Ela faz um discurso do fatalismo que recai sobre as pessoas que agencia, principalmente as que apresentam deformidades, conforme o próprio termo utilizado num de seus álbuns (ou cardápio). Tal discurso se apresenta como sistêmico, promovendo a culpabilidade e vitimização, enquanto também produz a docilidade desse outro que é diferente, para então estabelecer relação de subjugação, de dominação sobre o corpo outro e sua exploração, pois as vítimas dificilmente acreditam na possibilidade de encontrar acolhimento e afeto fora do espaço onde são exploradas. Talvez duvidem da sua própria humanidade, a qual entendemos que talvez seja procurada com uso de artefatos, como a personagem Laura que se apoia em seus diamantes rosas como substitutos dos olhos.

Ao mesmo tempo, quando nos atentamos à conversa de Ana com Ernesto quando diz: "Yo soy algo más que una mujer deforme [...] Las pieles cambian, las pieles se opera, se transforman. La apariencia física no es nada"7. Com tal posicionamento entendemos que também há no filme a problematização sobre a concepção de anormalidade e da própria noção de ser, ou nas próprias palavras, ela é mais do que uma mulher deforme, que a pele pode ser modificada, embora fique nítido no desfecho dessa personagem que não há o interesse de buscar a adequação aos padrões da corporalidade central.

Outro aspecto que não passou despercebido é que as personagens Laura, a garçonete e Vanessa são as únicas que sabemos sobre seus trabalhos e em quais funções esses corpos estão inseridos. Mas, em alguma medida, é suficiente para identificar que os corpos deformados e/ou anômalos são passiveis de serem explorados, principalmente no campo da sexualidade, do fetichismo ou do exótico, assim como em subempregos e condições degradantes de trabalho. Laura, por exemplo, desde criança fora

\footnotetext{
7 "Eu sou algo mais que uma mulher deforme [...] As peles mudam, as peles se operam, se transformam. A aparecia física não é nada". Tradução nossa.
}

Filos. e Educ., Campinas, SP, v.11, n.1, p. 36-61, jan./abr. 2019 - ISSN 1984-9605 
submetida à prostituição e tendemos a crer que fora abandonada ou mesmo negociada como objeto exótico junto a proprietária do prostíbulo.

Com apontamentos a partir do texto de Foucault "Os anormais" sobre os tipos monstruosos que borram as noções sobre leis na ordem jurídica e biológica, podemos também dizer que o filme Pieles causa a sensação de transgressão ou de violação dos padrões e ideais de normalidade. O autor Cavalcante (2017) em sua crítica ao filme nos diz que ele é "inteiramente provocativo, tudo nele irrita, incomoda e te faz ficar completamente desconcertado diante do que está sendo proposto". De nossa parte, não podemos negar o caráter provocativo do filme e que em determinadas cenas há perturbação e até mesmo repugnância.

Portanto, através do filme construímos uma relação entre os conceitos de corpo periféricos, ou das ideias de construção do corpo a partir das questões histórico-sociais, perpassando os conceitos de anormalidade e de anomalias, entendendo que estes também extrapolam os limites das ciências biomédicas, comumente apresentados de maneiras equivocadas para o imaginário e senso comum.

\section{Considerações finais}

Nossa proposta neste trabalho foi apresentar através das temáticas e personagens do filme Pieles de Eduardo Casonova reflexões e discussões sobre os conceitos de corpo, de normalidade e anormalidade. Foi um caminho teórico novo, além de muito complexo em suas concepções, sejam elas de caráter biológico, médico, psicológico, histórico, social e filosófico. O que não nos impediu de trilhar o que estabelecemos como caminho.

Portanto, buscou-se dialogar com teóricos que pudessem somar à nossa tese que não são as diferenças físicas/corpóreas, sejam elas anomalias ou mutações congênitas e outros tipos de deficiências físicas ou psicológicas, que definem os lugares e funções desses corpos/sujeitos diferentes na sociedade, mas sim os padrões, normas e convenções 
construídos histórico-socialmente pelos sistemas econômicos, políticos e científicos, atualmente, com predominância dos preceitos capitalistas e neoliberalistas, que normatizam os corpos, que os legitimam e que os excluem/incluem.

Ao definir essa normatização dos corpos pelos processos históricosociais a mercê do sistema social vigente, buscamos também apresentar como os conceitos de normalidade, anormalidade e patologia foram sendo alinhados pelos discursos hegemônicos das ciências biológicas e médicas, chegando ao senso comum. A intenção na argumentação destes temas foi de despatologizar corpos que são considerados anormais. Utilizamos os exemplos dos personagens do filme para mostrar que não são as anomalias ou deficiências de seus copos que os classificam como doentes, inaptos, aberrações, monstruosidades e incapazes/merecedores de viver e interagir socialmente como quaisquer outros, mas sim os mecanismos e instituições, um exemplo primário é a família, como agentes controladores e coercivos da ideia de normalidade.

Compreendemos que o filme poderia incorrer num lugar comum do entretenimento ou do fetichismo pelo exótico, que seria o de transformar-se num circo dos horrores ou das aberrações. Esse foi um dos pontos interessantes da crítica feita por Hackaq (2017) "como não deixar que o filme se torne puro fetichismo para a plateia "normal", ansiosa por ver pessoas deformadas como criaturas de circo?”.

Podemos salientar que o filme não teve uma preocupação em ser didático a respeito destas temáticas, ou seja, em explicar as origens e causas das deficiências ou anomalias de seus personagens, pelo contrário o foco não foram as anomalias ou deformações, mas sim os dramas que os personagens estavam vivendo como: preconceitos, rejeições, exclusões, violências, explorações e tantas outras angustias e sofrimentos possíveis, em consequência das ações normatizadoras do outro, ou seja, dos detentores dos corpos "normais", saudáveis e belos. Talvez um bom sinal de que o filme não tem sido visto como clichê e do exótico ao explorar estas temáticas é a produção deste trabalho. 
Nos desfechos das histórias dos personagens o filme parece refutar as afirmações feitas pela personagem proxeneta, de que a dor e sofrimento são natas para os e as que são diferentes, no contexto do filme, os e as deformados/as seriam aqueles/as nascidos/as para sofrer. Por mais que haja sofrimento e dor, há também alegrias, amor e momentos de felicidade como é passível de ser na vida de qualquer ser humano vivente. Finalizamos com uma frase que não é nossa, é de Hackaq (2017) ou que foi dita por ele: “Todas as peles humanas só desejam, por fim, se amar e ser amadas, e, às vezes, o ato de se amar é o mais difícil de todos".

\section{REFERÊNCIAS}

BÁRTOLO, José. Corpo e Sentido: estudos Intersemióticos. Covilhã- Portugal: livros Labcom, 2007.

CANGUILHEM, Georges. O normal e patológico. $\sigma^{a}$ edição. Tradução: Maria Thereza Redig De Carvalho Barrocas. Rio de Janeiro: Forense Universitária, 2009.

CARMELO, Bruno. Pieles A casa de bonecas deformadas. [2017-2018]. Disponível em < http://www.adorocinema.com/filmes/filme-241405/criticasadorocinema/>. Acessado em: 12/02/2019.

CAVALCANTE, Bruno. 'Peles', primeiro longa do espanhol Eduardo Casanova, surpreende e desconcerta o espectador, 2017. Disponível em $<$ https://www.blahcultural.com/critica-peles-primeiro-longa-do-espanholeduardo-casanova-surpreende-e-desconcerta-o-espectador/>; Acessado em? 12/02/2019.

FERNANDES, Luis; BARBOSA, Raquel. A construção social dos corpos periféricos. Revista Saúde soc. vol. 25, n. 1, 2016. Disponível em: http://www.scielo.br/scielo.php?pid=S010412902016000100070\&script=sci abstract\&tlng $=\mathrm{pt}>$

FOUCAULT, Michel. Os anormais: curso no College de France (1974-1975). Tradução Eduardo Brandão. São Paulo: Martins Fontes, 2001.

Vigiar e punir: nascimento da prisão. Tradução: Raquel Ramalhete. Petrópolis: Vozes, 1987.

HACKAQ, Gustavo. Crítica: nem os 50 tons de rosa escondem o lado obscuro do ser bumano no bizarro "Peles", 2017. Disponível em < 
https://www.portalitpop.com/2017/04/critica-nem-os-50-tons-de-rosaescondem.html> Acessado em 12/02/2019.

PIELES. Direção: Eduardo Casanova. España: distribuidora Premium Cine, 2007.

PLATT, Adreana Dulcina. Constructo conceitual de normalidade / anormalidade (ou da adequação social). Revista Quaestio. Sorocaba - SP, v.16, n.1, 2014. Disponível em $<$ http://periodicos.uniso.br/ojs/index.php/quaestio/article/view/1952 >. Acesso em 12/02/2019.

ROCHA, Everaldo; RODRIGUES, José Carlos. Corpo e consumo: roteiro de estudos e pesquisa. São Paulo: Editora PucRio, 2013.

Submetido em: 15/08/2019

Aceito em: 15/10/2019

Publicado em: 30/10/2019 